Chapman University

Chapman University Digital Commons

Communication Faculty Articles and Research

School of Communication

$4-25-2018$

Parasocial Romantic Relationships, Romantic Beliefs, and Relationship Outcomes in USA Adolescents: Rehearsing Love or Setting Oneself Up to Fail?

Riva Tukachinsky

Sybilla M. Dorros

Follow this and additional works at: https://digitalcommons.chapman.edu/comm_articles Part of the Communication Technology and New Media Commons, Critical and Cultural

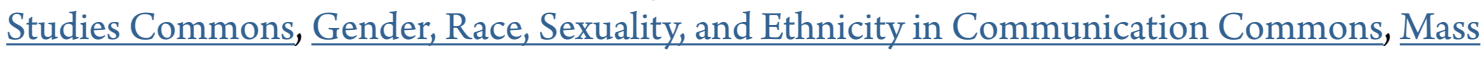
Communication Commons, and the Other Communication Commons 


\title{
Parasocial Romantic Relationships, Romantic Beliefs, and Relationship Outcomes in USA Adolescents: Rehearsing Love or Setting Oneself Up to
} Fail?

\section{Comments}

This is an Accepted Manuscript of an article published in Journal of Children and Media, volume 12, issue 3, in 2018, available online at DOI: 10.1080/17482798.2018.1463917. It may differ slightly from the final version of record.

\author{
Copyright \\ Informa UK Limited
}




\title{
Running head: PARASOCIAL ROMANTIC RELATIONSHIPS
}

Rehearsing Love or Setting Oneself Up to Fail? Parasocial Romantic Relationships in Adolescence and Romantic Beliefs and Experiences

\author{
Riva Tukachinsky \\ Chapman University
}

Sybilla M. Dorros

Chapman University 


\begin{abstract}
The study examines the associations between adolescents' emotional and physical aspects of parasocial romantic relationships with media figures, idealized romantic beliefs, perceptions of a current dating partner, and relationship satisfaction. A two-study design included concurrent data from 153 adolescents ages 13-17 (55.6\% female), and retrospective data from 274 college students ages 18-22 (79.8\% female). Across both samples, emotional involvement in a PSRR was related to more idealized romantic beliefs. The intensity of emotional involvement with the media figure during adolescence was associated with lower relationship satisfaction and less favorable perceptions of a current romantic partner in college students. However, there were no significant associations between physical attraction to the media figure and relationship outcomes. Keywords: Parasocial relationships, romantic relationships, adolescents, media effects
\end{abstract}


Rehearsing Love or Setting Oneself Up to Fail? Parasocial Romantic Relationships in Adolescence and Romantic Beliefs and Experiences

Past studies have shown that exposure to, and involvement with, romantically themed media, such as romantic movies and soap operas, is associated with adolescents' and young adults' idealized romantic expectations (e.g., Driesmans, Vandenbosch, \& Eggermont, 2016; Lippman, Ward, \& Seabrook, 2014). Building on this line of research, the current study explores romantic socialization through romantic involvement with media personae. In so doing, this investigation departs from theories of media exposure effects (e.g., cultivation), which examine effects of specific media content, and shifts attention to the socio-emotional-cognitive processes individuals can undergo outside of any given media context. Thus, the current investigation is no longer limited in scope to romantically themed media that have been exclusively studied in the past (e.g., Hefner \& Wilson, 2013; Segrin \& Nabi, 2002). Media consumers can form imaginary romantic relationships with characters from a variety of media outlets including music, sports, and non-romantic media (e.g., Allen \& Ingram, 2015; Tukachinsky, 2011). It is proposed here that the depth of the emotional involvement with, and physical attraction to, any media persona may foster individuals' relational expectations and potentially have implications for their dating experiences.

Additionally, despite the wealth of research on romantic beliefs, much less is known about media effects on actual relationship outcomes. The few studies that have investigated relational outcomes considered media exposure, rather than engagement with media figures, as the predictor (Osborn, 2012; Reizer \& Hetsroni, 2014). Therefore, the present study advances this field by investigating the psychological process of media consumers' emotional involvement 
with, and physical attraction to, a media figure during adolescence in association with romantic beliefs and relationship outcomes.

\section{Media and Idealized Romantic Beliefs}

A number of communication theories, including cultivation and social cognitive theory, suggest that exposure to, and engagement with, idealized media representations of romance lead to internalization of romantic beliefs (see Song \& Fox, 2016). Indeed, even young children articulate concrete romantic expectations that are heavily modeled after media representations of romance (Bachen \& Illouz, 1996). Several studies on college students found an association between exposure to romantically themed media (e.g., wedding-based reality TV, romantic comedies, soap operas) and endorsement of idealistic beliefs about romance (Hefner 2016; Hefner \& Wilson, 2013; Lippman et al., 2014). These media-based beliefs, in turn, can facilitate unrealistic marital intensions (Segrin \& Nabi, 2002). Moreover, exposure to idealized media portrayals of romance is predictive of poorer relational satisfaction, lower marital commitment, higher perceived costs of marriage (Osborn, 2012), and greater relational conflict (Reizer \& Hetsroni, 2014).

Notably, involvement plays an important role in these effects. For instance, Song and Fox (2016) revealed that Chinese women's involvement with characters in a romantic video game mediates the effect of exposure on romantic beliefs. Likewise, Driesmans et al. (2016) found that teenage Belgian girls' involvement with characters in a romantic teen movie was associated with subscribing to romantic ideals. The present study similarly stresses the importance of psychological involvement in romantic idealization. However, whereas previous research was guided by theories of effects of media representations of romance, the current study focuses on individuals' romantic involvement with media figures. Hence, the study is situated 
within theoretical frameworks of relationship experiences, rather than theories of media exposure effects.

\section{Parasocial Romantic Relationships}

Media consumers often form meaningful psychological bonds with media figures whom they have never met outside the media context. Such imaginary, one-sided relationships were dubbed parasocial relationships (PSRs; Horton \& Wohl, 1956). PSRs are psychologically similar to interpersonal relationships in terms of how they are cognitively managed and organized (e.g., Eyal \& Cohen, 2006; Eyal \& Dailey, 2012), and they can parallel various types of social relationships such as a friendships (Tukachinsky, 2011) and co-worker relationships (Stever, 2009).

One type of PSRs is parasocial romantic relationships (PSRR). PSRRs have been conceptualized as a two-faceted experience entailing physical attraction and strong romantic emotional feelings towards the media persona (Tukachinsky, 2011). This phenomenon has been documented in various ethnographic works, spanning from "crushes" on Elvis Presley (Fraser \& Brown, 2002) and Greta Garbo (Blumer, 1933) to Justin Bieber (Allen \& Ingram, 2015) and Edward, the vampire character in the Twilight Saga (2009-2012) (Pan, 2010).

Adolescents' PSRRs can be manifested by collecting pictures and posters of the beloved celebrity (Steele \& Brown, 1995) and connecting with other fans to reinforce their attachment to the media persona (Giles \& Maltby, 2004). For instance, YouTube users who identified themselves as 15-year-old girls professed love to Dr. House (a character in House, M.D., 20042012) and expressed jealousy in response to a video clip featuring their beloved character kissing another character on the show (Tukachinsky, 2011). Fandom art is another example of a 
common expression of this fantasy romance in adolescence. This includes, for example, creating a collage that depicts the teenager as Justin Bieber's girlfriend (Allen \& Ingram, 2015).

PSRRs are particularly common during teenage years and are most pronounced in girls (e.g., Theran, Newberg, \& Gleason, 2010). Adolescents' interest in celebrities begins to soar at the time when teens turn to their peers as their dominant socialization agent in lieu of their parents (Giles \& Maltby, 2004). It has been suggested that emotional attachment to media figures at this unique developmental stage serves an important psychological role in developing teenagers' identities (Stever, 2011). In the next section, we outline several reasons why adolescent PSRR experiences can play a role in relational beliefs and relationship experiences.

\section{PSRRs, Romantic Expectations and Romantic Relationships}

Social-cognitive theories collectively suggest that relational experiences inform individuals' beliefs about, and expectations from, future romantic relationships (e.g., Collins, 2003; Simon \& Gagnon, 1984; Sprecher \& Metts, 1999). Together, they constitute what the interdependence model calls a "comparison level" (CL) - a set of expectations and standards that are used to evaluate subsequent relationships (Rusbult, Arriaga, \& Agnew, 2001).

It is argued here that PSRRs might contribute to the formation of the CL similarly to faceto-face romantic relationships. The notion of PSRRs as an extension of romance in a nonmediated world is well established. PSRRs have been long thought of as a "placeholder" for actual relationships by offering a safe alternative to dating (Brown, Halpern \& L'Engle, 2005; Karniol, 2001; Ward, Day, \& Epstein, 2006). According to this view, PSRRs allow individuals to romantically experiment without being labeled promiscuous (which is especially important for adolescent girls) and shield the person from emotional threats of rejection or being hurt (Stever, 
2011). Hence, if interpersonal relationships guide relational beliefs and interactions in subsequent romantic relationships, so too can their parasocial equivalent.

This line of theorization diverges from media effects theories such as cultivation and social learning that explore the effect of exposure to, and involvement with, media representations of romance. Here, the internal psychological processes that occur when individuals engage in a fantasy-based romantic relationship (rather than observe a media portrayal of a relationship) promote beliefs through an imaginary interaction with the characters. In a sense, PSRRs in adolescence can be seen as comparable to children's pretend play experiences. Pretend play socializes children and allows them to assume different roles, while at the same time fostering metacognitions (Whitebread \& O'Sullivan, 2012). Similarly, in PSRRs, experiencing romantic relationships, even merely in one's imagination, enables the person to experience various emotions in response to the imaginary situation (as intracommunication research suggests, cf. Edwards et al., 1989; Honeycutt, Zagacki, \& Edwards, 1989). Engagement in these kinds of surrogate relationships presumably allows adolescents to crystalize their beliefs, preferences and expectations, and conceptualize themselves as sexual subjects, preparing them for future real-life relationships (Allen \& Ingram, 2015).

PSRRs and idealization. Provided that romantic experimentation in adolescence solidifies adolescents' romantic expectations and molds, to an extent, individuals' future romantic relationships (Collins, 2003; Collins, Welsh \& Furman, 2009), it is critical to consider the "lessons" propagated by these early relationships.

There are a number of reasons to expect that PSRRs would propagate unrealistic romantic beliefs. First, unlike regular relationships, PSRRs occur only in an individual's imagination. Thus, PSRRs are more likely to be a subject of optimistic biases and produce idealized 
expectations. PSRRs were conceptualized as a safe alternative for actual dating (Karniol, 2001) precisely because they involve fewer emotional risks such as rejection, relational violence, infidelity, and arguments. Anecdotal evidence stemming from qualitative studies on fans of movie stars and music artists supports this notion. It appears that fans' romantic fantasies tend to capitalize on positive aspects of a relationship with the media figure (e.g., getting married, Hinerman, 1992).

Second, public images of media figures are highly controlled and/or strategically manipulated to present them in the most favorable way (e.g., Gow, Lydecker, Lamanna, \& Mazzeo, 2012). Moreover, fans themselves construct and maintain an idealized image of the target of their PSRRs. For instance, fans have been shown to collect and share extensive picture galleries that represent their favorite celebrities, often in a hyper-sexualized manner (Soukup, 2006). Through this process of selective inclusion of pictures, the fans construct a particular image of the object of their fantasy. A similar pattern is evident in the example of Dr. House's fans described above. Although House's character is not sexualized in the television show itself, his adolescent fans referred to him on YouTube as "sexy as hell" and "charming" (Tukachinsky, 2011). These examples illustrate that attractiveness is subjective, and perceived characteristics of the media persona are more consequential than the actual media representation.

Finally, romantic ideals can originate from the media itself. The same romantic ideals uncovered in content analyses of romantic media (e.g., Hefner \& Wilson, 2013) are upheld by mainstream popular culture overall, including movies and TV shows that do not qualify as "romantic" (e.g., Batman Returns, 1992, Griffin, 2006), popular music (Dukes, Bisel, Borega, Lobato, \& Owens, 2003), and even commercials (Illouz, 1997). Media representations characterize love by powerful emotional and physical attraction and propagate ideals such as the 
ability of love to overcome all obstacles and perfect compatibility existing between partners. Hence, even if an individual engages in a PSRR with an actor/character featured in a "nonromantically-themed" production, the viewer is still likely to be exposed to romantic archetypes emphasizing relational and physical closeness that underlie the PSRR experience.

PSRRs and relationship outcomes. Exposure to media idealized depictions of romance has been linked to viewers upholding a higher CL, resulting in lower marital satisfaction (Osborn, 2012). It is also possible that a romantic parasocial experience can foster unrealistic relationship expectations, which in turn can lead to disappointment when the high standards are not met in reality. Given that PSRRs occur in a person's imagination infused by idealized media images of characters and romance, it is conceivable that they foster a CL next to which actual relationships seem disappointing.

For example, Horton and Wohl (1956) provide an example of a 23-year-old woman who divulged her inability to form relationships with men because they all pale by comparison to the television personality she fell in love with. In another example, a 32-year-old woman posted an online article professing love to the fictional character and blaming this PSRR for her inability to find a suitable partner (Davis, n.d.). Although extreme, these stories demonstrate the potential for PSRRs to advance unrealistic romantic expectations that leave media consumers less satisfied with their real-life romantic relationships. To our knowledge, no systematic empirical research has examined effects of PSRRs; only anecdotal-level evidence exists at the current time. The current study makes a step towards addressing this gap in the literature by examining the relationship between PSRR intensity, partner perceptions and relationship satisfaction.

\section{The Current Study}


The goal of the current investigation is threefold. First, the study explores whether the extent of PSRRs (conceptualized as intensity of physical attraction and emotional involvement) would be significantly associated with romantic beliefs. The tenacity of the imaginary romantic relationship that viewers form with the characters is expected to promote idealized beliefs. Specifically it is hypothesized that: Intensity of emotional and physical aspects of PSRRs will be positively associated with idealized romantic beliefs (H1).

Next, given that romantic relationships are shaped, to an extent, by prior romantic experiences (Collins, 2003; Rusbult et al., 2001), it is conceivable that adolescents' PSRRs will impact subsequent relational outcomes. PSRRs occur in a fantasy realm and therefore might result in a sense of disillusionment and disappointment when face-to-face relationships cannot live up to the ideals developed through PSRRs. Specifically, it is hypothesizing that: Intensity of emotional and physical aspects of PSRRs will be associated with lower relational satisfaction in current romantic relationships $(\mathrm{H} 2)$ and more unfavorable perceptions of one's current romantic partner (H3).

Finally, a mediation model is probed to ascertain possible indirect relationships between PSRRs, romantic beliefs and relationship outcomes. Building and expanding upon Osborn's (2012) application of the interdependence model to exposure to romantically-themed media, it is suggested here that PSRRs can set a standard to which subsequent romantic experiences are compared, resulting in a more critical view of one's actual relationship. That is to say, idealized romantic beliefs serve as a proxy for CL. We therefore ask whether the relationships hypothesized in $\mathrm{H} 2$ and $\mathrm{H} 3$ are mediated by romantic beliefs: Are the relationships between emotional and physical aspects of PSRRs and relational outcomes (satisfaction and partner's perception) mediated by romantic beliefs? (RQ1). 
To test the study hypotheses and research question, a two-study design was employed. First, Study 1 obtains concurrent self-report data from adolescents. However, only 40 adolescents in the sample reported having a romantic partner at the time of the study. This is consistent with the notion that adolescents' romantic relationships are transient and might lack the depth needed for examining relational outcomes. It is not until emerging adulthood (aged 1825) that individuals engage in meaningful and intimate romantic relationships (Arnett, 2000). Thus, it makes sense to examine the association between PSRRs in adolescence (as a form of romantic exploration typical to that stage) and experiences that emerging adults have in their first meaningful romantic relationships. Hence, relationship hypotheses $(\mathrm{H} 2-\mathrm{H} 3)$ and RQ1 were not tested on the adolescent sample. Instead, Study 2 utilized a sample of college students to replicate $\mathrm{H} 1$ and investigate associations between PSRRs and relationship outcomes.

\section{Study 1: Adolescent Sample}

\section{Procedures}

Data were collected using snowball sampling (word-of-mouth, social media, flyers) and a Qualtrics Panel. To be eligible to participate in the study, individuals had to be 13-17-years-old and reside in the U.S.. Upon obtaining parental consent and child assent, qualifying individuals were provided access to an online survey asking them about their PSRRs experiences, romantic beliefs, and demographic and psychological background variables. Additionally, attentionchecking questions were embedded in the survey to eliminate invalid respondents. Respondents in the snowball sample were emailed a \$5 gift card for their participation. Qualtrics Panel participants were compensated by the Panel provider in accordance with their policy.

\section{Participants}


Valid data were obtained from a total of 153 teenagers (snowball sample $n=36$, Qualtrics Panel $n=117)$ ages 13-17-years-old $(M=15.39, S D=1.38)$ from all 50 states throughout the U.S.. All age groups were represented: $14 \%$ were 13 -year-olds, $11 \%$ 14-yearolds, 25\% 15-year-olds, 20\% 16-year-olds, and the remaining 29\% were 17-year-olds. About half $(n=85,55.6 \%)$ were females, 63 males $(41.2 \%)$, and five individuals did not indicate their sex. The majority of the respondents (63.4\%) were White, 14.4\% Latino, 9.2\% African American, 6.5\% Asian, 2.6\% Native American, and the rest identified as other.

\section{Measures}

Participants were told that many individuals experienced "falling in love," having a "crush," or "romantic interest" in a media figure, and they were asked whether they had ever had such an experience. Most (72.5\%) of the participants had PSRRs. Specifically, 22.9\% had one PSRR, and 49.7\% had multiple PSRRs. If they had a PSRR once, they were asked to answer all the subsequent questions with that media figure in mind. If they had more than one PSRR, they were directed to respond about the most intense and meaningful one. Participants who did not have any PSRRs were asked to complete the questionnaire in reference to their favorite media figure. Because the current study is interested in the effect of the intensity of PSRRs (i.e., a PSRR as a continuous rather than a dichotomous construct), we report the results from the entire sample here, with non-PSRR targets adding to the variance on the variables of interest and the larger sample size increasing statistical power. However, analyzing the data only on the subset of respondents who reported a PSRR produced similar results (these results are reported in footnotes alongside the results section).

PSRR intensity. The intensity of the PSRR experience was measured using items from the Parasocial Love Scales (Tukachinsky, 2011). Emotional PSRR was assessed with four items, 
such as: "Sometimes I thought that X and I were just meant for each other" (range 1-7, $M=4.62$, $S D=1.62, \alpha=.92)$. The physical PSRR measure was comprised of four items, such as: "I am physically attracted to X" (range, $1-7, M=6.08, S D=1.24, \alpha=.95)$. All items were measured on a seven-point scale with higher scores indicating stronger romantic interest. Principal axis factoring with Oblimin rotation validated the factorial structure. Items' loadings ranged from .702 to .948 , with no meaningful cross-loadings $(\leq .217)$. The correlation between the two factors was .32.

Idealized romantic beliefs. Nine items measuring idealization of love, their partner and the strength of their relationship from Sprecher \& Mett's (1989) 15-item scale were used (e.g., "I'm sure that every new thing I learn about the person I choose for a long-term commitment will please me"). Items assessing belief in love at first sight were not included in this study because they are concerned with initiation of a relationship rather than relational maintenance which was of importance here. Items were measured on a seven-point scale with higher scores indicating more idealized beliefs (range 1.78-7, $M=4.84, S D=.89, \alpha=.79$ ).

Control variables. It is important to control for potential confounding factors, especially in a cross-sectional survey. Extant research has documented differences in socialization of boys and girls and potential socio-cultural differences concerning perception of relationships and dating (e.g., Giordano, Longmore \& Manning, 2006; Jackson, Sibyl Kleiner, Geist, \& Cebulko, 2011; Regan \& Anguiano, 2010; Neto \& Pinto, 2003). Additionally, relational beliefs are likely to evolve as individuals mature and as they gain more relationship experience, typically endorsing less idealized beliefs over time (e.g., Montgomery, 2005; Regan \& Anguiano, 2010). Furthermore, parental marital status can have implications for children's mental models of relationships, attachment, relational expectations and quality of their own subsequent romantic 
experiences (e.g., Feldman, Gowen, \& Fisher, 1998; Steinberg, Davila, \& Fincham, 2006;

Sprecher, Cate, \& Levin, 1998).

Thus, in addition to age, sex, and ethnicity, the current study controlled for parental marital status and relationship status and experience. Participants were asked to indicate whether their parents were married to each other or not; whether they are currently involved in a romantic relationship; and if they ever had a formal boyfriend or girlfriend. About half (55.6\%) reported that their parents were married. The majority $(61.4 \%)$ had a formal boyfriend or girlfriend (12 study participants did not respond to this question). Only 40 of all the respondents ( 32 of those with a PSRR) were in a relationship at the time of the study. Data were normally distributed.

\section{Results}

To examine the possible relationship between PSRRs and idealized romantic beliefs, a multiple regression was used. Respondents' age, sex (female vs. male), race (White vs. minority), parental marital status (married vs. not married), experience with dating, and current relationship status served as controls. Physical attraction to and emotional involvement with the media figure were used as predictors.

The multiple regression $\left(F(8,124)=2.48, p<.05, R^{2}=.14\right)$ revealed partial support for H1. There was no association between physical attraction and participants' romantic beliefs ( $\beta=$ $.10, B=.07$, S.E. $=.06, t=.68, p=.29)$. However, as expected, the intensity of emotional involvement with the media figure was positively associated with idealized romantic beliefs ( $\beta=$ $.26, B=.13$, S.E. $=.05, t=3.19, p<.01){ }^{1}$

\section{Study 1 Discussion}

Results of the adolescent sample are partially consistent with H1. Emotional engagement with the media figure (in particular, thinking of him or her as a romantic partner rather than as a 
sexual object) is associated with unrealistic relationship beliefs. It is therefore imperative to understand the implications these media-generated beliefs can then have for the media consumers' actual relational outcomes. Study 2 aims to replicate and extend the findings of Study 1 by examining the association between PSRRs and romantic beliefs as well as the relationship between PSRRs and real-life romantic experiences.

\section{Study 2: College Student Sample}

\section{Procedures}

College students were recruited to participate in a study about relationships in exchange for course research credit. The survey consisted of two online questionnaires completed 2-3 weeks apart. Participants were first asked to report the intensity of their PSRRs growing up using a prompt similar to the one used in Study 1. Two weeks later, participants received a link to the second part of the survey which asked about their romantic beliefs and if they were involved in a romantic relationship at the time of the study - questions about relationship satisfaction and current partner perception.

\section{Participants}

A total of 274 participants (79.8\% female) completed the two-part survey. Participants' mean age was 20.24 years $(S D=1.78)$. The majority of the respondents were White $(67.9 \%)$, followed by Latino (11.3\%), Asian (8.4\%), African American (1.1\%), and the rest identified as other. The majority $(64.2 \%)$ of the participants reported that their parents are married to each other. As in the adolescents sample, PSRRs were very common $(80.1 \%$ had at least one PSRR with 57.4\% reporting multiple PSRRs).

\section{Measures}


Intensity of PSRRs. The same scales and instructions employed in Study 1 were used to assess emotional and physical PSRRs (respectively: range 1-7, $M=3.92, S D=1.83, \alpha=.88$; range $1-7, M=6.02, S D=1.49, \alpha=.96)$. Principal axis factoring with Oblimin rotation accurately distinguished between the two factors. The factor loaded on their corresponding factors (loadings range: .519-.951), with no meaningful cross-loadings $(\leq .107)$. The two factors strongly correlated (.46).

Idealized romantic beliefs. The same items from Sprecher \& Metts (1989) as in Study 1 were used to measure endorsement of unrealistic romantic standards (range 2.11-7, $M=4.32, S D$ $=1.04, \alpha=.86)$.

Current romantic status. Participants were asked about whether they are currently involved in a romantic relationship. Participants who had a boyfriend or girlfriend at the time of the study $(n=97)$ were asked to respond to relationship satisfaction and partner perception measures as described in the following paragraphs.

Relationship satisfaction. Hendrick's (1988) Relationship Assessment Scale was used to measure respondents' current relationship satisfaction. The scale includes questions such as: “To what extent has your relationship met your original expectations?" Items were measured on a five-point scale with higher scores indicating greater relational satisfaction (range 1-5, $M=$ 4.03, $S D=.87, \alpha=.84)$.

Perception of current romantic partner. Participants were asked to rate their current partner on nine adjectives from the Mate Value Inventory (MVI-11; Kirsner, Figueredo, \& Jacobs, 2003). Items included: Attentive to partner, Emotionally expressive, Faithful, Generous, Give partner a say in relationship, Give the relationship high priority, Kind and understanding, Loyal, and Stable personality. For each adjective, participants were asked to rate their current 
partner on a scale from 0 (Not at all characteristic) to 10 (Very characteristic) (range 4.33-11, M $=9.78, S D=1.26, \alpha=.90)$.

Control variables. The same control variables as in Study 1 were used in Study 2 with the exception of experience with relationships, since all the college students indicated that they have had a formal boyfriend or girlfriend at some point.

\section{Results}

H1: PSRR and romantic beliefs. First, to replicate testing H1, a regression analysis was used with similar variables as in Study $1\left(F(7,146)=2.88, p<.01, R^{2}=.08\right)$. Intensity of emotional involvement with the media figure was positively associated with idealized romantic beliefs $(\beta=.30, B=.18$, S.E. $=.06, t=3.07, p<.01)$. A negative association with physical attraction approached significance $(\beta=-.20, B=-.15$, S.E. $=.08, t=-1.89, p=.06){ }^{2}$

Next, the possible association between PSRRs and relationship satisfaction $(\mathrm{H} 2)$ and the possible mediating role of romantic beliefs (RQ1) was examined using Hayes' (2013) PROCESS model 4 for SPSS with 95\% confidence intervals for bootstrap for 1,000 resamples. The model involves a series of regressions assessing the direct effect of the predictor (PSRR) on the mediator outcome (relationship satisfaction), and then examining its effect through a mediator (romantic beliefs). The intensity of emotional romantic interest in the media figure served as the independent variable. Here again, similar variables were used as control variables.

H2 and RQ1: PSRR and relational satisfaction. In predicting current relationship satisfaction $\left(F(7,56)=2.91, p<.05, R^{2}=.27\right)$, there was no relationship between physical PSRR and current relationship satisfaction (direct: $B=.05$, S.E. $=.10, t=.50, p=.62$, C.I. $[-.15, .25]$, indirect: $B=.05$, S.E. $=.04, z=1.37, p=.17$, C.I. $[.001, .18]$, total: $B=.10$, S.E. $=.10, t=1.06$, $p=.30$, C.I. $[-.09, .30])$. 
However, emotional PSRR were negatively associated with satisfaction $(B=-.18, S . E .=$ $.07, t=-2.41, p<.05$, C.I. [-.32, -.03]). The indirect effect was not significant $(B=-.04$, S.E. $=$ $.03, z=-1.34, p=.18)$, although the bootsrap C.I. do not overlap with zero [-.12, -.003]). The total effect was significant $(B=-.21$, S.E. $=.07, t=-2.97, p<.01$, C.I. $[-.36,-.07])$ providing partial support for $\mathrm{H} 2 .^{3}$

H3 and RQ1: PSRR and partner perception. Similar procedures were performed to examine the relationships between PRR and perception of the current romantic partner $(F(7,56)$ $=2.64, p<.05, R^{2}=.25$ ). Here again physical PSRR were not associated the outcome (direct: $B$ $=.08$, S.E. $=.15, t=.52, p=.60$, C.I. $[-.22, .38]$; indirect: $B=.01$, S.E. $=.05, z=.15, p=.88$, C.I. $[-.08, .12]$; total: $B=.09$, S.E. $=.14, t=.60, p=.55$, C.I. $[-.20, .37])$.

Conversely, emotional PSRRs were negatively associated with perception of the current romantic partner $(B=.30$, S.E. $=.11, t=-2.79, p<.01$, C.I. [-.51, -.08]). As with satisfaction, there was no significant indirect relationship $(B=-.01$, S.E. $=.03, z=-.15, p=.88$, C.I. [-.08, $.05])$. In line with $\mathrm{H} 3$, the total negative effect is significant $(B=-.30$, S.E. $=.101 t=-2.79, p<$ .01$, C.I. $[-.51,-.08]) .{ }^{4}$

\section{General Discussion}

The purpose of the current study was to examine whether individuals' emotional involvement and physical attraction to a media figure during adolescence were associated with idealized romantic beliefs and real-life relational outcomes in college students. For both adolescents and college students, study findings revealed a significant association between the intensity of participants' emotional attraction to PSRRs and idealized romantic beliefs. Further, for college students, the recalled intensity of the emotional PSRR during adolescence was associated with lower relationship satisfaction and less favorable perceptions of a current 
romantic partner. Taken together, study hypotheses were largely supported, demonstrating several ways in which PSRRs can be consequential in romantic socialization.

PSRRs and romantic beliefs. Results from both samples suggest that individuals who engaged in deeper emotional (but not physical) imaginary relationships with media figures have more idealized views of what romantic relationships and real-life partners should be like. These findings resonate with research investigating the relationship between exposure to romantic media content, idealized relational beliefs, and unrealistic relational expectations (e.g., Hefner \& Wilson, 2013; Segrin \& Nabi, 2002). However, this research explored learning of romantic ideals from observing romantic depictions in the media. Conversely, mental processes rather than media content were the focal point of the present study, therefore the investigation was not limited to romantically themed media content (for instance, in the current study participants reported having PSRRs with a basketball athlete and a fictional character from a hospital drama). Thereby, the study moves beyond examining the effect of media representations of romance to exploring the audiences' emotional engagement with media figures in the fantasy realms outside any particular media exposure context.

PSRRs and relational outcomes. Results of Study 2 partially supported the hypothesized association between PSRRs and relational outcomes. Specifically, the intensity of the emotional involvement with media figures (but not physical attraction) was associated with lower relational satisfaction and less favorable perception of one's current romantic partner. Importantly, this effect was not mediated by romantic beliefs. In other words, romantic beliefs and relational outcomes constituted two unique outcomes that operated independently of each other. Most likely, other mechanisms underlie the effect of PSRRs and perceptions of one's partner and relational satisfaction. For example, taking the social exchange approach (following 
Osborn, 2012), it is possible that the unobtainable standard promoted by PSRRs leads to exaggeration of perceived costs and trivialization rewards, which in turn diminish satisfaction with the romantic partner and the relationship. Although the exact process by which PSRRs can be detrimental to relational outcomes is yet to be pinpointed, the current findings are consistent with the theoretical framework and provide the first empirical evidence of the association between PSRRs and real-life relationships beyond anecdotal accounts.

Physical versus emotional facets of PSRRs. Interestingly, the results of the current study suggest that physical aspects of PSRRs do not play a significant role in romantic socialization of adolescents. There was no relationship between physical aspects of PSRRs and romantic beliefs among adolescents, and although this association was marginally significant for college students, the intensity of physical PSRRs was not linked to their relational satisfaction and partner perception. The difference between the predictive value of emotional and physical PSRRs can be attributed to a number of factors. First, sexual attraction could have implications for sexual, rather than emotional aspects of relationships that were of interest in the current study. Conceivably, outcomes such as perception of sex and sexuality, and self-objectification would be more likely to be associated with physical PSRRs. Alternatively, although physical attraction constitutes a component of romantic relationships, it can also be a manifestation of sexuality rather than romance. Conceivably, sexual relationships are not as impactful as emotional relationships. Indeed, Fisher (2004) maintains that romantic love is a powerful human drive that is substantially stronger than sex drive (e.g., depression, suicide, and homicide occur as a response to romantic rejection but not sexual rejection).

\section{Study Limitations}


Several limitations of the current study offer intriguing directions for further exploration. First, the starkest limitation of the current study is the reliance on cross-sectional data. In attempt to control for a time-order, college students in Study 2 were asked to reflect on their past PSRRs and report about their current romantic beliefs and relationship satisfaction. However, retrospective data is highly susceptible to recall and report biases. Moreover, few participants might have been still engaged in PSRRs at the time of the study. Consequently, similarly to past research in the field (e.g., Hefner, 2016; Lippman et al., 2014; Osborn, 2012; Reizer \& Hetsroni, 2014; Song \& Fox, 2016), the present study only offers correlational evidence of a relationship that is theorized to be a casual effect.

Accordingly, reverse causation cannot be ruled out. It is not improbable that teenagers who hold idealized romantic beliefs tend to develop particularly potent romantic attachment to media figures and then grow to be more romantically inclined young adults. For instance, biological and genetic individual differences might increase the propensity of some people to fall in love more intensely, and more often, than others (Fisher, 2004). Conceivably, people who are genetically inclined towards love would experience more intense PSRRs. Indeed, Hefner (2015) showed that adults may be seeking out romantic media that confirm their romantic dispositions. To control for time order, it is imperative for future research to collect longitudinal data following adolescents over several years. Such data could enhance internal validity by demonstrating the extent to which the evolution of romantic beliefs over time is associated with prior PSRRs while controlling for initial romantic beliefs.

Second, each of the studies' sample had its limitations. In Study 1, few adolescents were involved in a romantic relationship at the time of the study making it impossible to examine relational outcomes. In study 2 , a heterogeneous (and predominantly female) sample of college 
students was used. Nonetheless, that $\mathrm{H} 1$ received support using both samples is reassuring. Replications with larger and more diverse samples are warranted for further validation of the results, especially given the small sample size used for mediation analyses.

Third, the current study examined only two relational outcomes and a single mediator. Future studies could consider additional variables germane to understanding effects of CL, such as commitment and perceived rewards. Finally, future studies will benefit from including additional control or moderating variables. Most importantly they would include amount of media exposure and the length of the respondents' current romantic relationship.

\section{Future Research}

Despite its limitations, the study uncovers an intriguing association between PSRRs, romantic beliefs, and relational outcomes, and gives rise to new questions. For example, future studies employing longitudinal designs could reveal the persistence of the PSRRs. Study 2 demonstrated that college students' current dating relationship satisfaction is predicted by their PSRRs in adolescence. These participants are just a few years (and relationships) removed from the PSRR experience, but a few might have been still involved in that PSRR at the time of the study. Presumably, as individuals acquire more relationship experiences, new meaningful (faceto-face) relationships take priority in molding their romantic schema. It would be of importance to examine all PSRRs (not just the single most prominent one) and the interplays between them and actual experiences. Such longitudinal approaches would be critical in advancing understanding of the time sequence of the events and the relative contribution of different types of PSRRs, their duration and age at which they occur.

Future research could also consider the actual content of the media consumers' romantic fantasies. Two individuals can have a PSRR with the same media persona and find the exact 
same attribute of the media figure to be attractive. However, their romantic fantasies about that person and their imaginary relationship can give rise to different romantic scripts. For instance, a teenage girl's crush on a rebellious media figure could be experienced in her fantasies as a thrilling opportunity to cut loose with a wild partner or as a story of using the power of love to "rescue" him and transform his misguided behavior. These two distinct PSRR experiences rehearse different romantic scripts and can, therefore, result in different outcomes. Thus, further investigation of the details of the fantasy world that audiences create surrounding their beloved media figures can further illuminate the ways in which PSRRs produce various scripts that affect subsequent relationships.

\section{Conclusions}

Taken together, the current study adds to the existing body of literature on media's role in romantic socialization of adolescents by examining media consumers' PSRRs and demonstrating the value of future investigation in this domain. PSRRs were found to be extremely prevalent across both genders in this study. An overwhelming majority of participants in both samples reported "falling in love" or experiencing "a romantic crush" on a media figure. It therefore appears that PSRRs constitute a normal part of adolescents' sexual and romantic identity development. Yet, in line with past research on media and romance (Segrin \& Nabi, 2002; Reizer \& Hetsroni, 2014), the study findings suggest that PSRRs could potentially have undesirable ramifications for subsequent romantic relationships. Although correlational, the current study makes an important first step towards understanding the potential role of PSRRs in romantic development and advances new questions. 
Notes

${ }^{1}$ The results for the PSRR sub-sample are similar $\left(F(8,94)=2.95, p<.01, R^{2}=.20\right)$ revealed partial support for H1. There was no relationship between physical attraction and participants' romantic beliefs $(\beta=.07, B=.06, S . E .=.09, t=.68, p=.50)$. However, the emotional involvement with the media figure was positively associated with idealized romantic beliefs $(\beta=.32, B=.17$, S.E. $=.05, t=3.19, p<.01)$.

${ }^{2}$ Nearly identical results were obtained using the subset of only individuals who had a $\operatorname{PSRR}\left(F(7,117)=2.71, p<.05, R^{2}=.14\right)$. Emotional was positively associated $(\beta=.30, B=.19$, S.E. $=.06, t=2.99, p<.01)$ and physical attraction was marginally negatively associated $(\beta=$ $.20, B=-.23$, S.E. $=.11, t=-1.99, p=.05)$ with romantic beliefs.

${ }^{3}$ Similar results were obtained for a subsample of participants who had a PSRR. For predicting current relationship satisfaction $\left(F(7,40)=2.69, p<.05, R^{2}=.32\right)$, there was no relationship between physical attraction to the media figure on current relationship satisfaction (direct: $B=.01, S . E .=.15, t=.07, p=.94$, C.I. $[-.29, .31]$; marginal indirect effect: $B=.14$, S.E. $=.08, t=1.73, p=.08$, C.I. [.01, .37]; total: $B=.15$, S.E. $=.14, t=1.05, p=.30$, C.I. [$.14, .44])$. Emotional PSRR were negatively associated with satisfaction (direct: $B=-.18$, S.E. = $.09, t=-2.05, p<.05$, C.I. $[-.36,-.002]$; indirect: $B=-.06$, S.E. $=.04, z=-1.35, p=.18)$, however the bootsrap C.I. do not overlap with zero $[-.19,-.001]$; total $(B=-.24$, S.E. $=.09, t=-$ $2.64, p<.05$, C.I. $[-.42,-.06])$.

${ }^{4}$ Similar procedures were performed to examine the relationships between PRR and perception of the current romantic partner $\left(F(7,56)=2.89, p<.05, R^{2}=.33\right)$. Physical PSRR were not associated the outcome (direct: $B=.13$, S.E. $=.21, t=.67, p=.51$, C.I. [-.28, .55]; indirect: $B=.07$, S.E. $=.09, z=.78, p$ fo $=.43$, C.I. $[-.08, .33])$; total: $B=.21$, S.E. $=.19, t=$ 
$1.11, p=.27$, C.I. $[-.17, .59])$. Emotional PSRRs was negatively associated with perception of the current romantic partner (direct: $B=.30$, S.E. $=.12, t=-2.40, p<.05$, C.I. $[-.55,-.05]$; indirect: $B=-.03$, S.E. $=.04, z=-.70, p=.49$, C.I. $[-.19, .01]$; total: $B=-.33$, S.E. $=.12, t=-$ $2.75, p<.01$, C.I. $[-.57,-.09])$. 


\section{References}

Allen, L., \& Ingram, T. (2015). 'Bieber Fever': Girls, desire and the negotiation of girlhood sexualities. In E. Renold, J. Ringrose, \& D. Egan (Eds.), Children, sexuality and sexualization (pp. 141-158). Pilgrave Macmillan: London.

Arnett, J. J. (2000). Emerging adulthood: A theory of development from the late teens through the twenties. American psychologist, 55(5), 469.

Baldwin, M.W. (1992). Relational schemas and the processing of social information. Psychological Bulletin, 112(3), 461-484.

Bachen, C. M., \& Illouz, E. (1996). Imagining romance: Young people's cultural models of romance and love. Critical Studies in Media Communication, 13(4), 279-308.

Blumer, H. (1933). Movies and conduct. (p. 51). New York: The Macmillan Company.

Braboy Jackson, P., Kleiner, S., Geist, C., \& Cebulko, K. (2011). Conventions of courtship: Gender and race differences in the significance of dating rituals. Journal of Family Issues, 32(5), 629-652.

Brown, J. D., Halpern, C. T., \& L’Engle, K. L. (2005). Mass media as a sexual super peer for early maturing girls. Journal of Adolescent Health, 36(5), 420-427.

Collins, W. A. (2003). More than myth: The developmental significance of romantic relationships during adolescence. Journal of Research on Adolescence, 13(1), 1-24.

Collins, W. A., Welsh, D. P., \& Furman, W. (2009). Adolescent romantic relationships. Annual Review of Psychology, 60, 631-652.

Davis, K. (n.d.) Why MacGyver has ruined me for the average American male. Retrieved from: http://www.postmodernvillage.com/eastwest/issue16/16a-0004.html 
Dukes, R. L., Bisel, T. M., Borega, K. N., Lobato, E. A., \& Owens, M. D. (2003). Expressions of love, sex, and hurt in popular songs: A content analysis of all-time greatest hits. The Social Science Journal, 40(4), 643-650.

Driesmans, K., Vandenbosch, L., \& Eggermont, S. (2016). True love lasts forever: The influence of a popular teenage movie on Belgian girls' romantic beliefs. Journal of Children and Media, 10(3), 1-17.

Edwards, R., Honeycutt, J. M., \& Zagacki, K. S. (1989). Sex differences in imagined interactions. Sex Roles, 21(3-4), 263-272.

Eyal, K., \& Cohen, J. (2006). When good friends say goodbye: A parasocial breakup study. Journal of Broadcasting and Electronic Media, 50(3), 502-523.

Eyal, K., \& Dailey, R. M. (2012). Examining relational maintenance in parasocial relationships. Mass Communication and Society, 15(5), 758-781.

Feldman, S. S., Gowen, L. K., \& Fisher, L. (1998). Family relationships and gender as predictors of romantic intimacy in young adults: A longitudinal study. Journal of Research on Adolescence, 8(2), 263-286.

Fisher, H. (2006). The drive to love: The neural mechanism for mate selection. In R. J. Sternberg and K. Weis (Eds.), The new psychology of love. (pp. 87-115). New Haven, CT: Yale University Press.

Fraser, B. P., \& Brown, W. J. (2002). Media, celebrities, and social influence: Identification with Elvis Presley. Mass Communication \& Society, 5, 185-208.

Giles, D. C., \& Maltby, J. (2004). The role of media figures in adolescent development: Relations between autonomy, attachment, and interest in celebrities. Personality and Individual Differences, 36, 813-822. 
Giordano, P. C., Longmore, M. A., \& Manning, W. D. (2006). Gender and the meanings of adolescent romantic relationships: A focus on boys. American Sociological Review, $71(2), 260-287$.

Griffin, S. A. (2006). A qualitative inquiry into how romantic love has been portrayed by contemporary media and researchers. Doctoral dissertation, The Ohio State University.

Gow, R. W., Lydecker, J. A., Lamanna, J. D., \& Mazzeo, S. E. (2012). Representations of celebrities' weight and shape during pregnancy and postpartum: A content analysis of three entertainment magazine websites. Body Image, 9(1), 172-175.

Hefner, V. (2016). Tuning into fantasy: Motivations to view wedding television and associated romantic beliefs. Psychology of Popular Media Culture, 5(4), 307-323.

Hefner, V., \& Wilson, B. J. (2013). From love at first sight to soul mate: The influence of romantic ideals in popular films on young people's beliefs about relationships. Communication Monographs, 80(2), 150-175.

Hendrick, S. S. (1988). A generic measure of relationship satisfaction. Journal of Marriage and the Family, 50, 93-98.

Honeycutt, J. M., Zagacki, K. S., \& Edwards, R. (1989). Interpersonal communication, social cognition, and imagined interactions. In C. V. Roberts \& K. W. Watson (Eds.), Intrapersonal communication processes (pp. 166-184). New Orleans: Spectra.

Horton, D., \& Wohl, R. (1956). Mass communication and para-social interaction: Observations on intimacy at a distance. Psychiatry, 19(3), 215-229.

Hayes, A. F. (2013). Introduction to mediation, moderation, and conditional process analysis: A regression-based approach. Guilford Press. 
Hinerman, S. (1992). 'I'll be here with you: Fans, fantasy and the figure of Elvis.' In L. A. Lewis (Ed.), The adoring audience (pp. 135-159). New York: Routledge.

Illouz, E. (1996). Consuming the romantic utopia: Love and the cultural contradictions of capitalism. University of California Press.

Karniol, R. (2001). Adolescent females' idolization of male media stars as a transition into sexuality. Sex Roles, 44, 61-77.

Kirsner, B. R., Figueredo, A. J., \& Jacobs, W. J. (2003). Self, friends, and lovers: Structural relations among Beck Depression Inventory scores and perceived mate values. Journal of Affective Disorders, 75(2), 131-148.

Lippman, J. R., Ward, L. M., \& Seabrook, R. C. (2014). Isn't it romantic? Differential associations between romantic screen media genres and romantic beliefs. Psychology of Popular Media Culture, 3(3), 128-140. doi: 10.1037/ppm0000034

Montgomery, M. J. (2005). Psychosocial intimacy and identity: From early adolescence to emerging adulthood. Journal of Adolescent Research, 20(3), 346-374.

Neto, F., \& Pinto, M. D. C. (2003). The role of loneliness, gender and love status in adolescents' love styles. International Journal of Adolescence and Youth, 11(3), 181-191.

Osborn, J. L. (2012). When TV and marriage meet: A social exchange analysis of the impact of television viewing on marital satisfaction. Mass Communication \& Society, 15(5), 739757. doi: 10.1080/15205436.2011.618900

Pan, M. (2010). Bella should have dumped Edward: Controversial views \& debates on the Twilight series. Ulysses Press.

Regan, P. C., \& Anguiano, C. (2010). Romanticism as a function of age, sex, and ethnicity. Psychological Reports, 107(3), 972-976. 
Reizer, A., \& Hetsroni, A. (2014). Media exposure and romantic relationship quality: A slippery slope? Psychological Reports, 114(1), 231-249.

Rusbult, C.E., Arriaga, X.B., \& Agnew, C.R. (2001). Interdependence in close relationships. In G.J.O. Fletcher \& M.S. Clark (Eds.), Blackwell Handbook of Social Psychology: Interpersonal Processes (pp. 359-387). Oxford, UK: Blackwell Publishing.

Segrin, C., \& Nabi, R. L. (2002). Does television viewing cultivate unrealistic expectations about marriage? Journal of Communication, 52(2), 247-263.

Simon, W., \& Gagnon, J. (1984). Sexual scripts. Society, 22, 53-60.

Song, W., \& Fox, J. (2016). Playing for love in a romantic video game: Avatar identification, parasocial relationships, and Chinese women's romantic beliefs. Mass Communication and Society, 19(2), 197-215.doi: 10.1080/15205436.2015.1077972

Sprecher, S., Cate, R., \& Levin, L. (1998). Parental divorce and young adults' beliefs about love. Journal of Divorce \& Remarriage, 28(3-4), 107-120.

Sprecher, S., \& Metts, S. (1989). Development of the Romantic Beliefs Scale and examination of the effects of gender and gender-role orientation. Journal of Social and Personal Relationships, 6(4), 387-411.

Sprecher, S. \& Metts, S. (1999). Romantic beliefs: Their influence on relationships and patterns of change over time. Journal of Social and Personal Relationships, 16(6), 834-851.

Stackert, R. A., \& Bursik, K. (2003). Why am I unsatisfied? Adult attachment style, gendered irrational relationship beliefs, and young adult romantic relationship satisfaction. Personality and Individual Differences, 34(8), 1419-1429.

Steele, J. R., \& Brown, J. D. (1995). Adolescent room culture: Studying media in the context of everyday life. Journal of Youth and Adolescence, 24, 551-566. 
Stever, G. (2009). Parasocial and social interaction with celebrities: Classification of media fans. Journal of Media Psychology, 14(3), 1-39.

Stever, G. S. (2011). Fan behavior and lifespan development theory: Explaining para-social and social attachment to celebrities. Journal of Adult Development, 18(1), 1-7.

Soukup, C. (2006). Hitching a ride on a star: Celebrity, fandom, and identification on the world wide web. Southern Communication Journal, 71(4), 319-337.

Theran, S. A., Newberg, E. M., \& Gleason, T. R. (2010). Adolescent girls' parasocial interactions with media figures. The Journal of Genetic Psychology, 171(3), 270-277.

Tukachinsky, R. (2011). Para-romantic love and para-friendships: Development and assessment of a multiple-parasocial relationships scale. American Journal of Media Psychology, 3(1/2), 73-94.

Ward, L. M. (2003). Understanding the role of entertainment media in the sexual socialization of American youth: A review of empirical research. Developmental Review, 23(3), 347-388.

Ward, L. M., Day, K. M., \& Epstein, M. (2006). Uncommonly good: Exploring how mass media may be a positive influence on young women's sexual health and development. New Directions for Child and Adolescent Development, 112, 57-70.

Whitebread, D., \& O'Sullivan, L. (2012). Preschool children's social pretend play: Supporting the development of metacommunication, metacognition and self-regulation. International Journal of Play, 1(2), 197-213. 


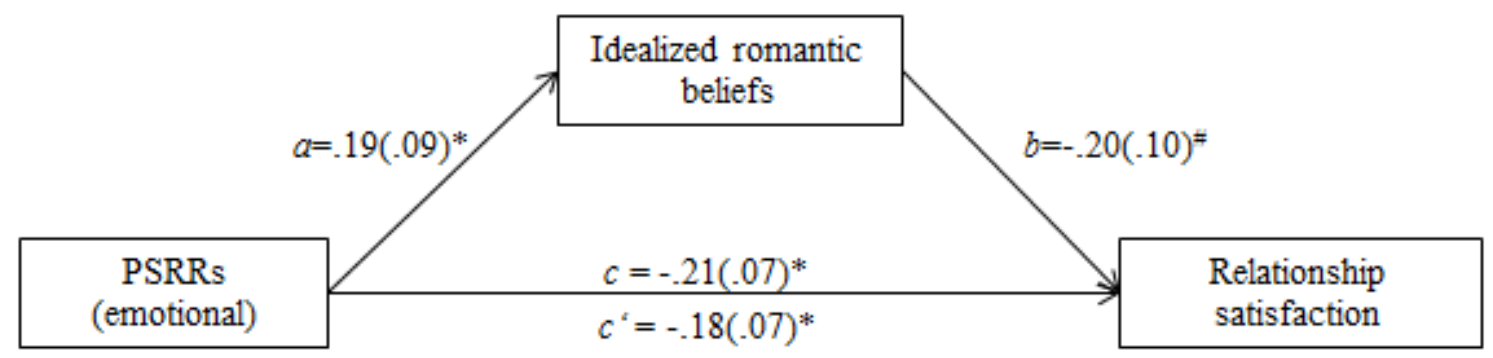

Figure la

Mediation model for PSRR, idealized romantic beliefs and relationship satisfaction.

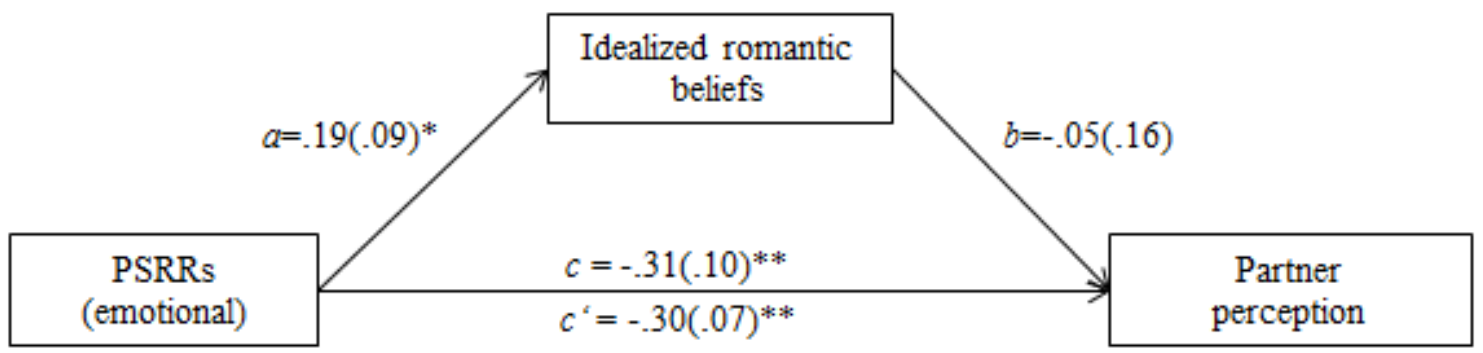

Figure $1 b$

Mediation model for PSRR, idealized romantic beliefs and partner perception. 